\title{
SOBRE LA REFORMA CURRICULAR: EL CASO DE ESPANOL Y LITERATURA*
}

\author{
Rubén Arboleda Toro
}

\section{INTRODUCCION}

Este estudio relaciona dos puntos de vista sobre la Renovación Curricular (Decreto 1002 del 24 de abril de 1986) que han captado y encauzado la atención de nuestro universo pedagógico: el de Carlos Vasco y el de un grupo de la Universidad Nacional presidido por Carlo Federici; señala convergencias y divergencias de ellos, en torno al Diseño Instruccional y los marcos generales de la Renovación; ubica en ese contexto las consideraciones sobre el Marco General de la nueva programación de Español y Literatura, para lo cual presenta algunos datos sobre la historia de este Marco, relaciona y evalúa los trabajos realizados sobre él, muestra, como los proponentes de los puntos de vista, que tiene bondades, pero destaca amplia y puntualmente sus limitaciones, para dejar clara la necesidad de una revisión seria de él, la importancia de desarrollar y formular propuestas pedagógicas para Español y Literatura, y para ponerle freno a una idea generada a lo largo de los debates y latente aún en el medio: el Marco del Area es adecuado; lo problemático es el diseño instruccional de los programas por curso y su relación con él.

Finalmente alude a tres momentos importantes en la construcción del conocimiento sobre la pedagogía de la lengua materna y la ausencia de esta referencia histórica en el Marco.

\section{El Diseño Instruccional ${ }^{100}$}

En relación con el Diseño Instruccional de la Renovación Curricular en general, y las implicaciones de su apropiación, el grupo de la Universidad Nacional (coordinado por Carlo Federici), ha venido presentando algunos trabajos ${ }^{101}$. Insiste en que la Reforma Curricular, a través del Diseño Instruccional elegido, reduce la práctica educativa a un conjunto de actividades dispuestas como medios para alcanzar una serie de logros preestablecidos" ${ }^{102}$; separa la concepción y diseño de los programas, de la ejecución de los mismos; reduce al educador, a través de esta separación, a un simple ejecutor de tareas milimétricamente diseñadas; por medio de las listas de objetivos específicos que se deben cumplir y evaluar milimétricamente, atomiza el proceso de enseñanza-aprendizaje e impide la posibilidad de orientarlo de acuerdo con situaciones de aprendizaje que se vayan presentando.

\footnotetext{
* Parte de estos contenidos fueron presentados en una ponencia verbal en el "V Seminario Nacional de Educación y Sociedad", organizado por CEPECS, Centro de Promoción Ecuménica y Social, en agosto de 1985. La ponencia fue transcrita y publicada en: CEPECS. Serie Reflexión Educativa, Cuadernos No. 6. Bogotá, 1986, Págs. 71-93.

${ }^{* *}$ Programa de Educación y Lenguaje. CIUP. Profesor Universidad Nacional.

${ }^{100}$ Los programas específicos por grado, diferentes al Marco General del área, están elaborados de acuerdo con un diseño instruccional que comprende: objetivos generales, específicos, contenidos, actividades y sugerencias metodológicas e indicadores de evaluación.

${ }^{101}$ FEDERICI, Carlo y otros. "La Reforma Curricular y el Magisterio" (publicado inicialmente en: Tribuna Pedagógica. Asociación Distrital de Educadores, ADE., Bogotá, No. 1, sin fecha, págs. 3-31) y "Puntualizaciones a la Reforma Curricular". En: Educación y Cultura. Federación Colombiana de Educadores, Fecode, Bogotá, No. 4, Junio de 1985, págs. 65-88 y 6-10.

MOCKUS, Antanas y otros. "Conocimiento y Comunicación en las Ciencias y en la Escuela". En: Educación y Cultura. No. 8, Julio de 1986, págs. 22-29.

FEDER 101, Carlo y otros. "Límites del Cientifismo en Educación”. En: Revista Colombiana de Educación. Bogotá, CIUP, No. 14, II Semestre 1984, págs. 69-90.

${ }^{102}$ Educación y Cultura, No. 8, pág. 23.
} 
Este punto de vista ha gozado de amplia complementación y difusión en el medio educativo; también ha sido objeto de controversia: Carlos Vasco, profesor de la Universidad Nacional, conocedor de la problemática educativa en general, discrepa ${ }^{103}$. Piensa él, por ejemplo, que no debe rechazarse por principio la tecnología educativa, entendida como "práctica social mejorada por la ciencia", sino que la tecnología educativa debe evaluarse para saber qué se debe incorporar dentro del programa de renovación curricular de un país, y qué se debe rechazar de una tecnología educativa, analizada a la luz de los principios que quieran regir la renovación pedagógica del país.

Textualmente dice:

"Me parece una cosa bastante útil como para no dejarse asustar ni en favor ni en contra de la Tecnología Educativa. Lo que hay que preguntar es: ¿De dónde viene esa Tecnología? ¿Qué ciencia alimenta ese tipo de técnica? Entonces ya puedo decir si me sirve o no me sirve y para qué me sirve. El Diseño Instruccional de corte funcionalista sí me parece que se ha quedado en hacer diagramas, desmenuzar pasos y seleccionar medios, y eso sí, efectivamente, aún por la sola malicia indígena, lo rechaza uno espontáneamente"104.

Considera que hay ciertos aspectos educativos, por ejemplo el aprendizaje de destrezas de rutina, de información verbal, el aprendizaje de una lengua extranjera, frente a los cuales es útil "la tecnología de refuerzo, de condicionamiento operante, de análisis de las tareas y de selección de medios". Claro que enjuicia "la extrapolación acrítica de esas tecnologías para todos los aprendizajes en todas las áreas"; y muestra otras tecnologías:

"Al empezar en la década del 60 el progreso de la sicología cognitiva con la recuperación de la escuela de la "Gestalt" de la escuela ginebrina y de la escuela soviética, y con el impulso de los modelos tomados de la lingüística chomskiana y de las ciencias de la computación ("Inteligencia Artificial"), se empezó a situar más apropiadamente el análisis experimental de la conducta en su verdadera ubicación dentro de la sicología, se aprovecharon sus aportes a la seriedad de la investigación, y se empezaron a explorar de nuevo esas fronteras oscuras y esos errores persistentes que resistieron el embate del conductismo. Las tecnologías derivadas de los resultados de la sicología cognitiva se han mostrado sumamente eficaces para lograr la comprensión, la reflexión crítica, la capacidad creativa, y el desarrollo de meta-estrategias para la resolución de problemas ".

y ejemplifica su aplicación:

"Con Marta Arango y Glen Nimicht, apoyándonos en las experiencias de Inés Arango en Sabaneta, Antioquia, y en cuatro poblaciones del Chocó, preparamos también una serie de juegos cognitivos para los dos primeros años de primaria, por encargo del Ministerio de Educación Nacional. Se necesitó una tecnología apropiada para que los juegos pudieran hacerse en cartulina de tal manera que cada niño pueda tener una colección completa de juegos por un costo mínimo; y

\footnotetext{
${ }^{103}$ VASCO, Carias. "Conversación Informal sobre la Renovación Curricular”. En: Educación y Cultura, No. 4, Fecode, Bogotá, Junio de 1985, págs. 11-18.

"La Reforma Tiene su Defensa". En: Tribuna Pedagógica. Bogotá, ADE, No. 4, Mayo de 1985, págs. 45-56.

"Límites de la Crítica del Cientifismo en Educación". En: Revista Colombiana de Educación. No. 16, II Semestre 1985, págs. 95114.

${ }^{104}$ Tribuna Pedagógica, No. 4, pág. 50.
} 
se necesitó una tecnología que realimentara las prácticas de juegos infantiles con una buena fundamentación tomada de la sicología cognitiva. Creo que hemos logrado una buena aproximación, y por las experiencias mencionadas de Sabaneta y el Chocó, sabemos que con estos juegos se logra una alta calidad en las relaciones del maestro con los niños, y de éstos entre sí, al mismo tiempo que se buscan objetivos muy específicos para desarrollar el pensamiento, las estrategias de resolución de problemas, la creatividad, la previsión, el manejo cualitativo de las probabilidades etc." ${ }^{105}$

En otra perspectiva, afirma la necesidad, para la unificación, de establecer contenidos y objetivos mínimos, y destaca la importancia de las sugerencias metodológicas de la Nueva Programación. Dice:

"En estas sugerencias metodológicas podría caber el documento de Integración Curricular puesto que una de las sugerencias metodológicas más importantes, es precisamente la de hacer los programas por unidades integradas"106.

En relación con la afirmación de la reducción del educador a un simple ejecutor de tareas, anota:

"...en los nuevos programas son precisamente los maestros los que son llamados a elaborar sus propias unidades integradas, recibiendo apenas orientaciones muy generales, los programas de las áreas y ejemplos más o menos acertados. Fue el fracaso del intento de diseñar detalladamente unidades integradas para todo el país el que empezó a introducir algunos cambios importantes en el estilo de trabajo de la Dirección General de Capacitación. Algunas evaluaciones de la manera como se estaban implementando en algunas escuelas experimentales las unidades integradas iniciales, hicieron ver que grupos de maestros que conocen bien su ambiente, con alguna asesoría y apoyo, pueden preparar sus unidades integradas con mayor sentido de adecuación a su medio y a sus alumnos de lo que podrían lograr los mejores técnicos y los más brillantes asesores científicos reunidos en una oficina en Bogotá. Pero también se pudo comprobar que sin los materiales y los ejemplos de unidades integradas producidos por los técnicos y asesores los maestros tampoco producían unidades a la altura de las que podían producir contando con esos apoyos" ${ }^{107}$.

Ciertamente la integración ofrece posibilidades interesantes a los educadores; inclusive, así lo señala el Grupo Federici, como lo veremos luego. Pero la Cartilla de Integración (fruto de un Seminario sobre el asunto, realizado por los programadores del MEN, bajo la Coordinación de Vasco, entre finales de 1981 y mediados de 1982), propiamente es posterior a la Versión final de los marcos generales de las Áreas (véase más adelante el numeral 3.2).

Por eso, los Programas, al menos los de Español y Literatura, se gestaron huérfanos de los principios de integración correspondientes, y éstos en cambio de aparecer como uno de los ejes de la Nueva Programación, aparecen como un apéndice, a partir del cual se puede caer en la práctica de elaborar unidades de área integradoras de los objetivos específicos y/o de los contenidos de los programas; esto alguna ventaja representa frente

\footnotetext{
${ }^{105}$ Revista Colombiana de Educación, No. 16, págs. 102 y 108.

${ }^{106}$ Educación y Cultura, No. 4, págs. 16, 17.

${ }^{107}$ Revista Colombiana de Educación, No. 16, págs. 104-105.
} 
a la simple ejecución de los programas objetivo tras objetivo, pero limita el conocimiento y las potencialidades del educador, no estimula su labor de productor de cultura y se interpone a la posibilidad de fundamentar las unidades en características del medio.

Como vemos, en lo relacionado con el diseño instruccional, y la tecnología educativa en general, estamos frente a un debate académico, cuyo estudio detenido y objetivo agita, enriquece y contribuye a la formación de nuestros juicios, y a la orientación de nuestras prácticas. Pertinente en relación con este asunto es el Cap. IV', Los métodos coactivos" del libro de Louis Not, Las Pedagogías del conocimiento, edición española del Fondo de Cultura Económica, México, 1983.

\section{Los Marcos Generales}

A pesar de los desacuerdos, hay puntos de contacto entre el Grupo y Vasco.

Resulta ahora pertinente insistir en uno relacionado con el marco teórico de la Renovación Curricular y los marcos generales de las áreas (contenidos en el denominado "libro amarillo"), diferentes a los programas específicos por curso.

Dice el grupo:

"De todas maneras, en la medida en que la integración trascienda la mera combinatoria de objetivos específicos, puede posibilitar actividades y proyectos interesantes tanto desde el punto de vista del conocimiento de lo regional y lo local, como desde el punto de vista político. Indudablemente, aunque limitado, éste es un espacio real abierto por el debate sobre la autonomía del maestro y es también, junto con el Decreto 26247 de 1984 sobre innovaciones, un primer paso para que el desarrollo de iniciativas propias del Movimiento Pedagógico pueda inscribirse en un marco legal".

Cuando habla de un buen espacio para este propósito, se está refiriendo a la Cartilla de Integración, que forma parte del paquete de la renovación.

Dice también:

"Mas sustancial es el desplazamiento (parcial) de la estrategia de difusión de Fa Reforma, por ejemplo, en los cursos de capacitación, hacia la presentación y discusión de los lineamientos generales y de los marcos teóricos. Esto es positivo e importante porque contribuye a que los maestros se apropien críticamente no del conjunto de instrucciones, sino de los principios que las fundamentan" $" 108$.

Insiste, entonces, en la importancia del contacto con los marcos generales, para que se llegue finalmente a una "apropiación de principios" en relación con el trabajo en un área y no exactamente a la apropiación de un número de instrucciones milimétricamente programadas.

Claro que el grupo Federici sintetiza los dos componentes de su punto de vista (importancia de los marcos generales e inconvenientes del diseño instruccional), al postular la contradicción entre ellos.

\footnotetext{
${ }^{108}$ Educación y Cultura, No. 4, págs. 9-10.
} 
"Por otra parte, existen flagrantes contradicciones entre la adopción, por parte de la Reforma Curricular, del diseño instruccional como fórmula de bajo costo para el 'mejoramiento de la calidad de la educación' y una serie de elementos de los discursos que hacen parte del dispositivo de presentación de la Reforma ('lineamientos generales' y 'marcos teóricos'). Este dispositivo de presentación tiene un carácter predominantemente defensivo y puede interpretarse como una concesión de los expertos (tecnocráticamente orientados) a sectores (más 'humanistas') que consideran necesario que los maestros accedan al dominio de principios teóricos más profundos desde los cuales puedan juzgar y eventualmente estructurar ellos mismos su propia práctica. Desde el punto de vista de los técnicos parece poco realista esperar que el maestro alcance ese dominio. Por ello, ellos prefieren poner al maestro a seguir una serie de instrucciones muy detalladas (ofreciendo en el caso límite un 'currículo a prueba de maestro'). Aunque lamentablemente los discursos de presentación de la reforma esquivan cualquier referencia seria, argumentada, a la opción por el diseño instruccional, las contradicciones entre esa opción y los mensajes explícitos (pedagogía activa, niño como sujeto de procesos de conocimiento) pueden generar interesantes procesos de cuestionamiento, discusión e interpretación"109

Y como resultado de la discusión de los marcos, posee importantes reflexiones críticas sobre los de Matemáticas y Ciencias Naturales. Estas fueron presentadas en el Primer Simposio Nacional sobre la Enseñanza de las Ciencias, realizado en 1981. Parte de ellas se reproducen en Educación y Cultura No. 9, Septiembre de 1986. pág. 10-24.

El año pasado decíamos que el debate sobre la renovación curricular en el tiempo más inmediato, se podría polarizar en torno a las posiciones Grupo Federici-Vasco ${ }^{110}$. Encontramos que la idea continúa vigente; y sirve, aún, para situarse ante una postulación reciente del grupo Federici:

"Dos iniciativas ocupan actualmente un primer plano en el terreno de la educación en el país, al menos en lo que respecta a la educación básica: la Reforma Curricular y el Movimiento Pedagógico. No sólo se diferencian por el papel que otorgan al maestro y los límites que atribuyen a la intervención del Estado en la práctica pedagógica; tienden a distinguirse también por el modo en que conciben el carácter mismo del proceso educativo"111.

En los trabajos sobre Español y Literatura se ha comenzado a percibir la situación, como lo veremos luego.

Vasco, a su vez opina:

"Lo más importante es la primera pata del trípode: el marco teórico (el trípode se refiere a marco teórico, contenidos y objetivos y metodología); este aparece en los 'Fundamentos Generales del Currículo', el llamado 'LIBRO AZUL', donde está el marco teórico general (. . .) y en el libro 'LIBRO AMARILLO', los marcos generales en donde está cada área con su marco teórico. Para mí, estos son los

\footnotetext{
${ }^{109}$ Educación y Cultura, No. 8, pág. 23.

${ }^{110}$ ARBOLEDA, Rubén. En: CEPECS, Ob. Cit. pág. 77.

${ }^{111}$ Educación y Cultura, No. 8, págs. 22-23.
} 
documentos más valiosos que ha producido hasta ahora el grupo del currículo formal".

Dice luego:

"Lo más importante desde el punto de vista conceptual son los marcos teóricos, y por esto me parece que es allí donde se debería dar el debate más serio" ${ }^{112}$.

En este punto hay que insistir, porque juntó a los debates en relación con la estructura específica de cada programa, conviene establecer un debate serio en relación con el marco teórico en el que esos programas se fundamentan.

Se percibe que aún cuando no está en desacuerdo con los programas específicos de cada área y con el diseño instruccional que ellos poseen, tiene, como el Grupo Federici, su mirada preferencialmente enfocada hacia los marcos generales, y considera que es en ellos donde realmente está lo mejor de la propuesta del Ministerio de Educación.

\section{El Marco General del Área de Español y Literatura ${ }^{113}$}

También nosotros vimos desde cuando trabajábamos en la DIE (Dirección de Investigaciones Educativas del Distrito), la importancia para la enseñanza de la lengua del acercamiento al Marco General de Español y Literatura, y de organizar la capacitación docente alrededor de él. Ya en un documento del año 82, decíamos del Programa, refiriéndonos al Marco General, que aventajaba la programación anterior (1710), en lo relacionado con teoría del lenguaje, metodología y con la insistencia en el desarrollo del conocimiento y de las habilidades de comunicación, y que era un documento útil, en muchas de sus partes, en cuanto guía general para el docente de Español (Ver CEPECS, Ob. Cit.).

Pero no es esta la razón fundamental por la cual hemos traído las opiniones en mención. Lo hicimos para señalar que al menos en Español y Literatura es necesario insistir en que si bien el Marco General presenta elementos útiles, requiere una revisión seria. Es justo cerrarle paso a una idea de alguna manera potenciada: el Marco es adecuado; lo problemático es el diseño instruccional de los programas por curso y su relación con él.

Por eso, nos ocupamos, de manera más amplia que en otras ocasiones, por un lado de las virtudes del Marco (benéficas en sí para cualquier propuesta pedagógica, y oportunas para la inscripción de ésta en un marco legal), pero por otro, de los aspectos que ameritan aclaración, precisión, reorientación, complementación, e incluso otras propuestas.

Nuestra meta es la construcción progresiva de propuestas integrales. Para ello resultaría positivo que este análisis del Marco generara un diálogo en el contexto de esta propuesta de Vasco:

\footnotetext{
${ }^{112}$ Educación y Cultura, No. 4, págs. 16-17.

${ }^{113}$ MINISTERIO DE EDUCAC1ON NACIONAL, Colombia. Marcos Generales de los Programas Curriculares. Bogotá, 1984, págs. 33-139.

Su estructura es:

- Introducción: pág. 33-35

- Enfoque del Área: pág. 35-54

- Objetivos Generales del Área: pág. 54-56

- Estructura del Área: pág. 56-57

- Contenidos Básicos de i a IX: pág. 58-69

- Metodología (incluida la evaluación): pág. 70-139. 
"Si en los textos de los Fundamentos Generales del Currículo, de los Marcos Generales de los programas, en los programas mismos o en los materiales de apoyo van apareciendo elementos heterogéneos, arbitrarios e inconsistentes, me comprometo en cuanto esté de mi parte a revisarlos cuando se señale especificamente... "114.

\subsection{Evolución de los Estudios sobre el Marco General}

Nuestro trabajo de 1982 comienza a señalar los aciertos y limitaciones del Marco. Desafortunadamente, en documentos de circulación muy restringida (ver nota 9).

Un primer artículo de Gloria Rincón y Carmen Rosa Ortíz elaborado en el contexto de las reflexiones iniciales del grupo Federici, encuentra adecuado el Marco (no señala nada contrario) pero no materializable en los programas, debido, según las autoras, a que el diseño instruccional no es compatible con el ideal de maestros y alumnos creativos, productores de pensamiento, que encarna el enfoque semántico-comunicativo de aquel. Ilustra la afirmación a partir del programa de lecto-escritura (primer grado). Dice:

"Nos parece entonces, que los programas (de lecto-escritura) tienen una fundamentación teórica que posibilita una verdadera <transformación' en la práctica pedagógica en esta área, lo cual hace pensar que se trata de una redención para la educación, pero más adelante cuando se analicen los programas veremos las fallas que se presentan y las incongruencias entre el Marco Teórico y el quehacer educativo que se institucionaliza"115.

En 1985 nosotros continuamos insistiendo en los aciertos, pero también limitaciones, del Marco ${ }^{116}$.

Los trabajos posteriores hacen referencia, como el de Gloria y Carmen Rosa, a las contradicciones Marco-Diseño Instruccional. Pero, a diferencia de ellas, comienzan a centrar la atención en las inconsistencias y otras limitaciones al interior mismo del Marco (como lo veremos en la sección dedicada a limitaciones), con lo que se va ampliando esa dimensión del análisis que habíamos abierto ${ }^{117}$.

En el momento de entregar este escrito, apareció en Educación y Cultura No. 9, "La Lengua Materna en la Escuela y la Reforma Curricular", de Gloria Rincón y otros. De manera pertinente, amplían y concretan su consideración sobre la contradicción entre el Marco y los Programas por grado, atendiendo ahora a los de lo., 2o. y 3o. e insinúan unas ideas, de carácter general y rápido, para una propuesta de trabajo. Registramos con

\footnotetext{
${ }^{114}$ Revista Colombiana de Educación, No. 16, pág. 105.

${ }^{115}$ RINCON, Gloria y ORTIZ, Carmen Rosa. "La Reforma Curricular y los Programas de Lacto-escritura". En: Educación y Cultura, No. 4, Bogotá, Fecode, Junio de 1985, pág. 35.

${ }^{116}$ ARBOLEDA, Rubén. En: CEPECS, Ob. Cit.

${ }^{117}$ ROMERO, Ana Rita. Los Retos de la Enseñanza del Español y la Literatura. En: CEPECS, Ob. Cit. págs. 5-57.

CORRALES, María Teresa y otros. Análisis y Propuesta Pedagógica sobre el Programa de Español y Literatura Propuesto por el M.E.N. para el Grado 3o. de Educación Básica Primaria (sic.), Bogotá, Universidad Externado de Colombia, 1985 (fotocopia).

Se trata de un ejercicio presentado en una materia. Aporta ideas útiles pero requiere mucha elaboración tanto en el contenido como en la composición. Trabaja el programa de Tercero. Ofrece ideas para una propuesta pedagógica fundamentada en la "teoría del desarrollo".

BARRERO, Luz Mary y TORRES, Martha Yanira. Análisis del Desarrollo de los Programas Curriculares para el Área de Español en la Educación Básica Primaria a partir del En foque Semántico-Comunicativo. Bogotá. Universidad Nacional, Filología e Idiomas, 1986 (fotocopias).

Trabajo de grado. Como el anterior, requiere elaboración en contenido, argumentación, composición, etc.
} 
satisfacción que, además, en este artículo reformulan explícitamente su posición en relación con la excelencia del Marco: rechazan la <'concepción racionalista de la lengua", "la concepción sausureana del lenguaje", la metodología de la enseñanza de la lectura y la escritura y los criterios de evaluación; de otro lado, encuentran que se desatiende la función comunicativa del lenguaje, y en consecuencia, el contexto comunicativo.

En contraste con el artículo de Educación y Cultura No. 4, exageran algunas críticas; por dar un ejemplo, las relacionadas con la normatividad. Llama la atención la transición de un reconocimiento total a un rechazo total del Marco.

Es de esperar que, desde diferentes puntos de vista, se continúen y afinen los estudios del Marco en sí, y los comparativos de éste y los programas por grado. Y que los educadores sigamos presentando, de manera cada vez más sistemática, propuestas específicas.

\subsection{Algo de Historia del Marco}

De la misma manera que los programas, el Marco General tuvo varias versiones, tres por lo menos, la primera de las cuales es del segundo semestre de 1977. Trabajaron en ella Ana González, Margarita de Herrera, Margarita de Angarita (en menor proporción, Argelia Aguilar), con una asesoría intensa de Carlo Federici. Fue una versión relativamente breve y sencilla, que esencialmente establecía una diferencia entre el lenguaje como instrumento de comunicación y el lenguaje como objeto de estudio; proponía un trabajo en la primaria centrado en el lenguaje como instrumento de comunicación, y en la secundaria compartido entre el estudio del lenguaje como objeto y el desarrollo de las habilidades comunicativas; daba algunas orientaciones con relación al desarrollo de las cuatro habilidades; buscaba que el niño empezara a comprender que con la palabra se hace referencia a la realidad (objetos, cualidades, procesos, relaciones); y hacía un énfasis especial en el abordamiento de la literatura.

Durante el año de 1977 se estructuraron y empezaron a ensayar programas para primero, segundo y tercer grado de primaría. Dice una de las programadoras que en ese momento el diseño no fue cuestionado, sino más bien aceptado en cuanto acción impulsada desde ja Dirección General y la División de Currículo Formal, por Pilar Santamaría de Reyes y Clara Franco de Machado respectivamente; seguramente, esto contribuye a explicar las incoherencias Marco-programas por grado (Ver numerales $3.1 \mathrm{y}$ 3.4). También dice que llegaron algunas críticas de los maestros, "sin mucha fuerza argumentativa", referidas sobre todo al propósito de no centrar durante la primaría la atención en el lenguaje como objeto de estudio (gramática).

A partir de esta versión se llega a la de 1981. Adopta los elementos esenciales de la versión-77, y los enmarca en el enfoque lingüístico conocido con el nombre de semánticocomunicativo. Para entonces se habían vinculado Doris Amparo de Rodríguez y Sara Agudelo de Pabón, quien traía los elementos del enfoque, de su posgrado de Lingüística en la universidad del Valle, dirigido por el profesor Luis Ángel Baena. Y había ingresado (desde 1978) Carlos Vasco como asesor de los programadores, en reemplazo de Federici. Parece que el comportamiento frente al diseño instruccional no varió significativamente en los programadores.

Esta versión también produjo confusiones y desconciertos. Se decía, por ejemplo, lo que busca la reforma "es acabar con la gramática en la escuela", "sustituir una 
terminología (sustantivo, adjetivo, verbo y adverbio) por otra (objetos, eventos, cualidades y relaciones)", etc.

Con base en el estudio de estas versiones, algunos profesores del Distrito y los "técnicos" del Area de Español de la DIE-CEP, le presentamos inquietudes y recomendaciones al M.E.N., a finales de 1981, a través de la DIE (Ver Anexo No. 1).

Algunas de las consideraciones tenían aún un carácter incipiente; otras eran discutibles; pero de todas formas aportaban elementos útiles.

En febrero de 1982 sale una tercera versión. Sustancialmente corresponde a la anterior; pero la amplía y la precisa. Acoge algunas de las insinuaciones señaladas en el Anexo No. 1, pero, como en otras áreas deja de lado unas de carácter fundamental. Precisa algunos datos con base en una evaluación del Instituto Caro y Cuervo y en unos comentarios de prensa (El Siglo, El Tiempo, Junio de 1981). Los programadores son fundamentalmente los mismos. En el Anexo No. 2 destacamos sus particularidades en relación con la Versión-81.

Y en agosto del mismo año sale una cuarta versión. En este momento se había retirado Sara Agudelo de Pabón y había sido reemplazada por Enrique Cabeza, autor del Taller de Ortografía publicado por Educar Editores y de una Serie de Textos para la Educación Básica, en compañía de Miguel Peñaloza (profesor de ja Universidad Pedagógica Nacional), publicada por Norma. La versión de febrero esencialmente se conserva. Por lo demás se [imita a reordenar y suprimir información, esto último sin explicar criterios justificatorios (Ver Anexo No. 2) y a introducir: un cuadro completo de los fonemas y letras del español (págs. 40-49), una nota de pie de página acerca del grupo fónico (pág. 52) y un paso para la identificación del significado literal de un texto: "Buscar en el diccionario las palabras cuyo significado sea desconocido" (pág. 69).

Esta versión de agosto es la que posteriormente pasa al libro de los Marcos Generales. En cuanto éste se concibió como un documento de consulta, de capacitación para los docentes, y se vio en él uno de los productos más importantes de la Renovación Curricular, tal vez la versión más apropiada para llegar a él hubiera sido la de febrero de 1982, dada su mayor riqueza de datos. Según informaciones del propio Ministerio, buena parte del presupuesto para ja publicación de los materiales de la Renovación fue desviado, por lo que se hizo necesaria la mutilación.

\subsection{Bondades del Marco General}

Insistamos primero que todo en que nuestro análisis se centra en el Marco General, y que nuestro reconocimiento a los aspectos destacables de éste no son extensivos automáticamente a los programas específicos de los grados, no jos valida; no hemos hecho un análisis detenido de ¡a coherencia Marco-programas.

Efectivamente, el Marco General representa un avance en relación con la programación correspondiente a los Decretos 1710 de 1963 y 080 de 1974; de la que, justamente, Carlos Vasco dice:

"Ya los programas para la educación primaria promulgados por el Decreto 1710 de 1963 fueron diseñados con el estilo de objetivos generales y objetivos 
específicos conductuales que se exigía como el único científico en la educación"118.

Y en otra parte:

“...ya al finalizar ese Gobierno (del doctor Misael Pastrana Borrero) se hizo una reforma de los programas de bachillerato (Decreto 080 de 1974) de una manera improvisada"119.

Entre los trabajadores del lenguaje han surgido ya afirmaciones sobre el enfoque semántico-comunicativo, en cuanto característica específica e innovadora de ja nueva programación, respaldadas en un mayor o menor conocimiento de él. Y efectivamente, ¡as bondades fundamentales se relacionan con este enfoque, no obstante las jimitaciones con que la nueva programación lo presenta, que, por supuesto no pueden imputársele.

Comprendemos, por supuesto, que las bondades a las que nos vamos a referir no son todas las destacables, sino las que por nuestra formación, experiencia y nuestros propósitos, encontramos dignas de ser subrayadas. Sabemos que muchas han sido impulsadas desde antes y en otros medios; pero de todas formas, el Marco General destaca una serie de aspectos positivos acerca del lenguaje y su pedagogía, cuya puesta en marcha contribuiría al mejoramiento de la educación:

4.4.1. Introducir unos elementos semánticos, funcionales y pragmáticos del lenguaje e insistir en su vivenciación, posterior teorización y no sacrificio ante un abordamiento estrictamente morfosintáctico de la lengua. Ellos son:

- Las nociones de foco, información compartida por los hablantes (vieja) y no compartida (nueva). (Marco General, p. 13 y 19).

— La relación lenguaje-realidad, lenguaje-pensamiento, lenguaje-cultura, lenguajeemotividad. El establecimiento de conexiones entre la palabra (lo que se dice) y los objetos, cualidades, procesos y relaciones que se dan en la realidad natural y social, y entre los componentes oracionales y los objetos agente, paciente, beneficiario e instrumento. Temática ésta que no es completamente nueva en ja lingüística (p. 39-48 y 90-94).

— La explicitación de funciones específicas del lenguaje: expresión de necesidades; regulación de la conducta; establecimiento de relaciones diferenciales con los demás; ja manifestación de opiniones, sentimientos, la propia identidad, la manera de pensar sobre el mundo y de apreciarlo; la explicación de la realidad y la apropiación de conocimientos; la imaginación y la fantasía (p. 44-45).

Realmente, la presencia de estos aspectos no es fruto de una arbitrariedad de la programación, sino del justo centramiento de la atención en el significado y en el uso del lenguaje, que se ha operado en la lingüística contemporánea. Y ha ¡do conduciendo a cuestionamientos interesantes (por ejemplo, el de la diferencia entre las categorizaciones morfosintácticas y las categorizaciones semántico-referenciales) y al contacto con

\footnotetext{
118 VASCO, Carlos. "El Enfoque de Sistemas en el Nuevo Programa de Matemáticas". En; Revista de la Universidad Nacional, Bogotá, Vol. 1, No. 2, 1985, pág. 45.

${ }^{119}$ Educación y Cultura, No. 4, pág. 12.
} 
desarrollos recientes de la lingüística, que rebasan el acercamiento tradicional de la escuela al lenguaje.

Al margen de ja Renovación Curricular y de los juicios sobre su validez, esta perspectiva merece atención.

4.4.2. Centrar el trabajo de la educación básica primaria en el desarrollo de las habilidades comunicativas (habla-escucha> lectura-escritura), para todo tipo de actividades: de la vida cotidiana, científica, artística, etc.; privilegiar esta práctica en relación con la de transcripción y memorización de nociones sobre la gramática, muchas veces inaccesibles al educando, por el estado de desarrollo de éste, y otras veces, decimos nosotros, imprecisas cuando no anacrónicas ${ }^{120}$. Reservar el estudio de la teoría lingüístico-literaria para cuando el educando haya logrado el desarrollo, la capacidad de abstracción, necesarios para ello (p. 33, 38, 39, 70, 71, 72, 76, 92, 128).

El Marco General aporta datos de Piaget sobre la relación pensamiento-lenguaje, que ayudan a comprender este planteamiento y a establecer momentos apropiados para ja enseñanza de la gramática (p. 49-53).

Insiste en la constitución y explotación de la biblioteca escolar (p. 115-116), y en una tarea tan importante para el desarrollo del pensamiento y la expresión, como es la producción de los periódicos escolares (p. 119-120).

4.3.3. Identificar el estado de desarrollo del educando, las experiencias $>$ conocimiento que lleva, capacidades, así como las jimitaciones y dificultades para, a partir de ellos y de su adecuado abordamiento, lograr un trabajo productivo (p. 72, 85, 86).

3.3.4. Desarrollar correlativamente las habilidades comunicativas: realizar ejercicios de composición escrita con base en prácticas orales sobre el mismo tema, etc. (p. 72. 73, 74, $86,87,90)$. Practicar ja producción y comprensión tanto de signos lingüísticos como no lingüísticos (señales de tránsito, vallas, mapas, gestos, etc.), (p. 38-94, 95).

4.3.5. Adoptar criterios apropiados para la selección de lectura y para las orientaciones que en este sentido se le den a los educandos (p. 99, 101).

4.3.6. Realizar prácticas comunicativas mediante la lengua viva de los educandos, respetando y estimulando su palabra, y en torno a realidades naturales y sociales que jes sean significativas, que sean de su interés, que hayan sido vividas, experimentadas, observadas. A partir de lo anterior irse acercando poco a poco a otros niveles del lenguaje y a realidades nuevas. Lo anterior fundamentado en ideas de Piaget acerca del desarrollo del pensamiento (p. 39, 71, 72, 74, 85, 86, 100, 101).

4.3.7. Promover la expresión libre en todos ¡os niveles, pero lograr propiedad, coherencia, precisión en el vocabulario y en los datos, ortografía y puntuación adecuadas.

\footnotetext{
${ }^{120}$ En Educación y Cultura, No. 8, pág. 24, el Grupo Federici, a propósito del "énfasis reciente en la adquisición de habilidades, destrezas y actitudes", dice: "En énfasis en habilidades, destrezas y actitudes puede llevar, en efecto, a hacer de los saberes objeto de enseñanza un mero pretexto, 156 Revista Colombiana de Educación desplazando a un segundo plano el reconocimiento de las pretensiones de verdad y de coherencia que acompañan necesariamente a esos saberes". Estamos de acuerdo. Nosotros aplaudimos la idea de centrar la enseñanza del lenguaje de la Básica Primaria en el desarrollo de las habilidades comunicativas, pero entendido esto como la puesta en marcha de prácticas comunicativas tales que desarrollen el conocimiento del universo. Al respecto tenemos algunas consideraciones en: ARBOLEDA, Rubén. "La Enseñanza del Español como Lengua Materna". En: Revista Colombiana de Lingüistica. Bogotá, Vol. II, Nos. 2-3, 1983, págs. 136-145.

"El Referente y el Desarrollo de las Habilidades Comunicativas". En: Revista Lenguaje. Cali, Universidad del Valle. No. 13, 1982, págs. 47-72.
} 
Esto mediante la autoevaluación, coevaluación, comentario, reelaboración de las producciones; y mediante la creación de situaciones auténticas de comunicación que hagan pensar en el lector; producción, exhibición, difusión en otros centros educativos, en la comunidad, e intercambio de periódicos escolares y otras publicaciones.

4.3.8. Estimular en el educando la capacidad para disfrutar de la literatura. Ponerlo en contacto con la literatura, inicialmente, a través de las lecturas y narraciones del maestro. Estimularle ja producción, para lo que propone guías metodológicas de creación, y clarificar que el éxito no depende de la incomprensibilidad o de la retórica del lenguaje utilizado. Seleccionar una auténtica literatura infantil y acercar al educando a historias, leyendas, costumbres y antepasados regionales y nacionales (p. 100-1 15).

4.3.9. Finalmente, en cuanto a los objetivos generales del Area para la educación básica, conviene señalar que se adecuan a los principios del Marco. Este insiste en tres aspectos: el desarrollo de las habilidades comunicativas, el disfrute de la literatura y el acercamiento a ella como medio de conocimiento, y la visión de la semántica y la función del lenguaje, y entre el cambio semántico y los cambios en la realidad. A su vez, los objetivos generales de cada curso están comprendidos en los generales del área, y son formulados teniendo en cuenta al alumno como centro del Programa.

4.3.10. Las profesoras Carmen Rosa Ortíz y Gloria Rincón encontraron Importantes algunos de estos aspectos, y otros que voy a señalar. Dicen refiriéndose a los beneficios del Marco General:

"Parte de la realidad comunicativa del alumno, o sea, tiene en cuenta los conocimientos que sobre su lengua posee el niño al llegar a la escuela, buscando ampliar y desarrollar esas habilidades. No se hace por lo tanto, una separación tajante entre el lenguaje ordinario del alumno y el de la escuela (el de la norma), permitiendo de esta manera una reflexión directa sobre la lengua de uso habitual".

"Al tener en cuenta la enseñanza de la lengua, 'basados en una concepción de la producción lingüística humana', se pretende estudiar la lengua no solo en lo que ella es, y cómo funciona sino también para qué sirve" (sic).

"Se parte en la enseñanza de la lengua del nivel referencial, porque éste tiene relación directa con la realidad que se maneja: para el niño es más fácil distinguir objetos, cualidades, procesos, relaciones; conocimientos empíricos que maneja en su lengua y que se dan en realidad objetiva. A medida que avanza (en el nivel referencial) empieza a hacer abstracciones de su lengua pasando al nivel gramatical, el cual se le dificulta, puesto que las categorías de la realidad no corresponden una a una a las categorías gramaticales".

"Tiene en cuenta correlacionar la enseñanza del lenguaje con las otras áreas de estudio, para que el alumno comprenda el que el conocimiento no se da aislado del lenguaje y en gran medida está mediatizado por el discurso que lo expone" (sic).

"Este Marco Teórico, como vemos, está orientado hacia una práctica pedagógica donde el alumno no sea un simple receptor sino que participe en forma activa en ¡a producción y creación del saber; pretendiendo cambiar la relación unilateral que se maneja en la escuela, donde el alumno es un experto en repetir 
conceptos y definiciones sacados por otros. Esta nueva práctica permite al niño hacer sus nuevas creaciones, pensar, participar en la elaboración de conceptos y definiciones, es decir, reconocerlo como un 'constructor' de su propio saber"121.

\subsection{Limitaciones del Marco General}

Acá las tratamos en forma general y breve, debido a que venimos realizando análisis y propuestas en relación con ellas, que por su naturaleza y extensión merecen un tratamiento aparte. Algunas de las apreciaciones son retomadas de documentos nuestros de 1982 y 1985.

4.4.1. En la relación entre el Marco General de la Renovación Curricular y el Marco del área se registran incoherencias. Este posee vacíos en la materialización de principios fundamentales contemplados por aquel: integración de áreas, vinculación de los padres de familia al proceso pedagógico, etc.

Existe la Cartilla de Integración, terminada en junio de 1982, otro resultado de las afortunadas incursiones frente a la "línea tecnológica-conductual", señaladas por Vasco, que de alguna manera responde a las consideraciones de los educadores sobre la atomización de los procesos de enseñanza-aprendizaje, generada por el diseño instruccional. Infortunadamente, ella propiamente es posterior a la versión final de los Marcos. De ahí la horfandad de principios de integración que acompañó la redacción de los programas, al menos el de Español y Literatura, a pesar de las solicitudes al respecto (ver Anexo 1). Ya dijimos que un rudimento presente en la versión del Marco de febrero de 1982, fue eliminado en la de agosto. Quedan algunas insinuaciones, no explicitacíones, en las páginas 39, 71, 74.

Un ejemplo: Las unidades 2, 3, 4 del programa de sexto grado presentan objetivos y actividades en los que se destaca la yuxtaposición, pero no una estructura, una secuencia coherente orientada por propósitos definidos: En la unidad 2 encontramos referencias a: relación lenguaje-pensamiento y realidad; constituyentes inmediatos de la oración simple (actividad: analizar programas de radio y televisión); lectura comprensiva en forma oral y silenciosa (actividades: diligenciar cheques y formularios, redactar cartas y telegramas comerciales, elaborar memorandos y consignaciones); analizar mitos, leyendas y tradiciones; la hipérbole ${ }^{122}$.

Es esperable una adecuación al respecto, en nuevas versiones, en los programas por grado que poco a poco está produciendo el Ministerio, y también en las propuestas de los educadores $^{123}$.

El informe final del Seminario sobre integración en el diseño curricular realizado en el MEN en 1982, habla sobre la necesaria revisión del diseño curricular; claro que el Diseño se oficializa en 1984, sin que esto hubiere sucedido. Dice el informe:

“...se hace necesaria la revisión del diseño curricular que está en experimentación. Esta revisión plantea por lo menos dos tareas prioritarias:

\footnotetext{
${ }^{121}$ Educación y Cultura, No. 4, pág. 35.

122 MINISTERIO DE EDUCACION NACIONAL. Programas Experimentales de Español y Literatura, Sexto Grado de Educación Básica Secundaria (sic.). No posee más datos. Según nota marginal, es una "versión 1985" (fotocopias).

${ }^{123}$ De manera un tanto intuitiva y todavía rudimentaria, pero ya habíamos comenzado a trabajar en ese sentido. Parte de la experiencia se recogió en: "El referente y el desarrollo de las habilidades Comunicativas". En: Revista Lengua/e. Cali, Universidad del Valle, No. 13, 1982, págs. 47-72.
} 
Primera: determinar políticas y estrategias más precisas para el rediseño, teniendo en cuenta:

- Las críticas formuladas a la tecnología educativa en los últimos anos.

- Las experiencias ganadas en la misma programación y experimentación del actual diseño curricular.

— La discusión psicológica y pedagógica alrededor de los métodos de ‘Escuela Activa.

La determinación de estas políticas y estrategias debe adelantarse hasta lograr una coherencia que supere la mera hibridación ecléctica.

Segunda: clarificar criterios de integración para el desarrollo del currículo experimental"124.

No conocemos los desarrollos del MEN en este sentido; estamos a la expectativa.

4.4.2. Desde hace varios años, el profesor Luis Angel Baena, de la Universidad del Valle, trabaja en la construcción de un modelo para el acercamiento a la Semántica del Lenguaje. En el momento actual, el trabajo ha logrado bastantes desarrollos significativos; sus logros han sido presentados de manera integral en dos Seminarios realizados en Bogotá: uno organizado por la DIE (1984), y el otro por la Universidad Distrital (1985). Considera que en las lenguas existen tres niveles de significación: referencial, lógico y socio-cultural ${ }^{125}$.

El Marco adopta el enfoque en mención; desafortunadamente, de manera inconveniente, sobre todo si se tiene en cuenta el poco conocimiento que los destinatarios tenían sobre el asunto. Aquí, como en lo referente a la psicología piagetiana, la adopción es esquemática y fragmentaria: no hace referencia explícita a los tres niveles de significación. Tiene en cuenta fundamentalmente el primero, el referencial, y aporta datos breves relacionables con los otros dos: información nueva, información dada, funciones del lenguaje, lenguaje y emotividad, lenguaje y cultura, etc. Pero de manera esquemática; sin ubicación en la totalidad de niveles; incorporando datos aislados, descontextuados, huérfanos de esa clara visión integracionista del lenguaje y de los aportes de la lingüística, que se respira al estudiar las conferencias de Luis Angel.

Quizás esto se explique porque los programadores del MEN contactaron el enfoque en su etapa inicial, y no han seguido los desarrollos del profesor Baena (fruto de un trabajo cotidiano) y de la semántica en general; o, porque no tuvieron ocasión de complementar el Marco, debido al retiro de algunos programadores, a las necesidades de publicación (lo que deja ver la imposibilidad de tener Marcos no reajustables), o a otras circunstancias.

Alguien podría argumentar que se tomó básicamente el nivel referencial por ser el más apropiado para el trabajo con niños, dado su estado de desarrollo cognitivo ${ }^{126}$. $Y$ efectivamente, parece que el MEN pensó inicialmente sólo en la programación para la

\footnotetext{
${ }^{124}$ MINISTERIO DE EDUCACION NACIONAL. Colombia. Seminario sobre Integración eh el Diseño Curricular. Bogotá, D.E., junio de 1982 (mimeo).

${ }^{125}$ Ver: El Lenguaje en Relación con sus Funciones Esenciales en el proceso de Adquisición del Conocimiento y en el Proceso de la Comunicación. Transcripción hecha por la DIE-CEP, de la grabación de las conferencias dictadas por el profesor Baena. 110 páginas tamaño oficio.

${ }^{126}$ En este sentido, y refiriéndose a los fundamentos del Marco General, las profesoras Rincón y Ortíz, de Cali, dicen: "Se parte en la enseñanza de la lengua del nivel referencial, porque este tiene relación directa con la realidad que se maneja: para el niño es más fácil distinguir objetos, cualidades, procesos, relaciones: conocimientos empíricos que se maneja en su lengua y que se dan en su realidad objetiva". Educación y Cultura No. 4, pág. 35.
} 
Básica Primaria (tal vez a eso se deba la referencia continua del Marco a los niños). Pero pronto enfocó la Básica Secundaria, donde se espera un contacto con los niveles Superiores de significación. No obstante, aun cuando se trabajara para la Básica Primaria, la totalidad era necesaria, primero, porque el Marco va dirigido a los educadores, y segundo, porque la comprensión de cada nivel depende de, o por lo menos, se enriquece con la captación del significado como sistema de tres dimensiones.

Pero es más, en los datos sobre el nivel referencial aportados por el Marco se perciben imprecisiones:

Considera que "la realidad está constituida por objetos (seres, elementos, cosas) y procesos (eventos, hechos, sucesos, acontecimientos), cualidades de los objetos y de los procesos y por las relaciones que se dan entre ellos". Y contempla la clasificación de las palabras según que refieran a objetos, procesos, cualidades de objetos, cualidades de i5rocesos y relaciones, bajo la convicción de que así se va comprendiendo, sin teoría, la relación existente entre lenguaje y realidad (págs. 40-41). Hasta ahí es claro. Pero no diferencia satisfactoriamente, palabra y referencia. En una de las ediciones se leía: "En la cadena hablada y escrita, objetos, eventos, cualidades y relaciones interactúan, por ejemplo, el gato juega alegremente con la pelota roja (sic.).

En la página 41 del actual dice: "Se consideran objetos todas las personas, animales, plantas, minerales, las cosas construidas por el hombre y las cosas hechas por los animales que existen en el universo. Por ejemplo: Alaría escribe con el lápiz, El gato juega con la pelota, La rosa es bella, La piedra es filuda, La casa de Pedro, El nido del águila, La gente salió corriendo. María, lápiz, gato, pelota, rosa, piedra, casa, Pedro, nido, águila y gente son objetos". En la 92: "Es necesario que comprenda la relación entre lo que se dice y los objetos, las cualidades y los procesos (eventos, sucesos o acontecimientos) que se dan en la realidad; por ejemplo: Juan escribe con su lápiz azul una carta a su papá. Encontramos que: Juan, lápiz, carta y papa son objetos que existen en la realidad.

Y en la página 77 del programa de quinto grado, de la edición de 1982: "El maestro hará que los niños identifiquen los objetos agentes ejecutores de la acción (aquellos nombres que responden a la pregunta ¿quién lo hace?), en oraciones como Juan corta leña...".

Resulta muy orientador, precisar que en la cadena hablada y escrita interactúan signos referentes a objetos, eventos, cualidades y relaciones; que María, lápiz, etc. no son esos objetos sino que se refieren a ellos; que los nombres "que responden a la pregunta ¿Quién lo hace?" se refieren a los “objetos-agentes ejecutores de la acción”, pero no son los “objetos-agentes ejecutores de la acción'>, pertenecientes al universo extralingüístico. Es muy saludable para el propósito de un cambio de enfoque no generador de confusiones, ser meticuloso en esta distinción.

En las primeras ediciones del Marco se utilizaron exclusivamente verbos para ejemplificar palabras referentes a eventos, adjetivos para cualidades y sustantivos para objetos; lo que crea un terreno propicio para la indistinción de estas categorías, que, como veremos, son relacionables, pero diferentes.

Tal vez esas características de la adopción del enfoque, unidas a la yuxtaposición de ciertas huellas dejadas por las diferentes etapas y personas del Marco (Carlo Federici, Ana González y Margarita de Herrera en un primer momento; Sara Agudelo de P. y otros en un segundo momento; etc.), expliquen las inconsistencias y desconexión entre 
elementos, de manera más apropiada que la idea de la indefinición frente a las concepciones lingüísticas, como se ha proclamado en otros trabajos. Porque a pesar de las huellas es evidente la opción por el enfoque semántico-comunicativo; y no es tal indefinición una propiedad atribuible al modelo en construcción del profesor Baena, ni a los trabajos de Tito Nelson Oviedo (también, profesor de la Universidad del Valle), que de alguna manera fundamentaron la programación, sobre todo a través de la entusiasta y consecuente acción de programadores, alumnos de ellos en el postgrado de la Universidad del Valle, o asesorados en otros espacios. Si esto resulta ser así, requiere solución. Una vía puede ser el compromiso con la presentación y difusión integral y sistemática del enfoque, y de su relación con otros; de sus posibilidades de integración: por ejemplo de la sintaxis con la semántica, de la noción de sistema con la de proceso; de las consecuencias pedagógicas de su adopción; etc.

4.4.3. También hay fallas, como tantas veces se ha dicho, en las relaciones entre el Marco del área y los programas. Realmente, en los programas es frecuente la atomización del proceso de enseñanza aprendizaje de la lengua materna (ya lo insinuamos en el numeral 4.4.1):

4.4.3.1. Aparecen objetivos específicos que suponen experiencias no tenidas antes, o que se ocupan una sola vez de prácticas que deben ser permanentes.

Uno de los programas propone el enriquecimiento léxico en objetivos específicos iniciales del curso. Eso está bien. Pero el enriquecimiento léxico no es algo que se da en las dos primeras semanas de clase. Es un trabajo que se da correlacionado con el enriquecimiento del conocimiento de universo y que por tanto es una práctica continua. Por eso, en ciertos momentos aparece demasiado artificiosa la separación, la dedicación de un objetivo a una destreza, exclusivamente. Por ejemplo, en segundo se dedica un objetivo, aisladamente, a la entonación. Eso no tiene razón de ser, porque este ejercicio debe ser precedido de uno de comprensión del texto que se va a leer, que a su vez exigirá seguramente un análisis del significado de algunas palabras. Esto que cito como ejemplo su-cede en muchos de los objetivos que parten de texto escrito.

Igual consideración hace el grupo de Gloria Rincón cuando se refiere no sólo a la circunscripción a, sino a la "dosificación" de los contenidos sobre las categorías de la realidad y su relación con la palabra (Educación y Cultura, No. 9, págs. 29 y s.s.).

4.4.3.2. Siendo uno de los derroteros del Marco el desarrollo correlativo de las habilidades comunicativas, resultan inconsecuentes:

— Objetivos específicos aislados, dedicados ampliamente y de manera exclusiva, por ejemplo a la entonación o a los matices de la voz.

- Prácticas iniciales de lectura oral, que no contemplan la fase de preparación, de lectura silenciosa (Marco, págs. 98 y 108), cuando la comprensión es un factor para el logro de una entonación adecuada, y cuando en las situaciones auténticas de lectura oral la realidad no es así.

— Insuficiente atención al trabajo de ortografía, léxico, etc., a partir de los textos producidos por los alumnos; a la adecuación de aquellos en relación con destinatarios específicos (convenidos en el curso) a quienes se dirigen; a la práctica de lectura en torno a ellos. 
3.4.3.3. El acercamiento esquemático al enfoque conduce a que los programas de la Primaria y los educadores mismos terminen privilegiando el trabajo de identificación y categorización de palabras, ahora según un criterio semántico-referencial, no morfosintáctico, pero que de todas formas rival iza con el propósito de centrar la atención en el desarrollo de la competencia lingüística del educando a través de prácticas comunicativas continuas. $\mathrm{Y}$ no enfatiza otras prácticas pedagógicas que derivan naturalmente del enfoque: el contacto con los referentes objeto de la práctica comunicativa, la recolección y sistematización de datos acerca de ellos, su puesta en común, la sistematización de ellos, la escritura a partir de dichas prácticas, el habla y la escritura como interacción, la percepción de las funciones que cumple el discurso, etc.

4.4.4. En la Básica Primaria es fundamental el desarrollo de las habilidades comunicativas. Pero resulta inconveniente no insistir, al lado de esto, en el conocimiento, lingüístico y no lingüístico, que se construye y adquiere a través de las prácticas comunicativas.

4.4.5. Posee datos útiles, pero sueltos. No presenta una propuesta integral, en el sentido de estructurada, coherente, sobre el lenguaje y su pedagogía, ni sobre la producción de unidades que contemplen el desarrollo de las habilidades comunicativas y el conocimiento del universo. Tampoco esboza perspectivas de investigación; por ejemplo de la escritura en la escuela: ¿acto de pensamiento o simple transcripción bancaria, depositaria?

4.4.6. Temas que por su importancia para el desarrollo de las habilidades de comunicación y por la posibilidad de aplicar logros de la lingüística y de otras disciplinas en su tratamiento, merecerían una especial consideración, o por lo menos una remisión bibliográfica, no se tocan o se presentan de manera ortodoxa y simple: la tipología de los textos, el resumen (pág, 89), incluso la puntuación (pág. 83), el folclor literario (copta, leyenda, mito, etc.), la lectura (pág. 96 y s.s.), la corrección lingüística (a pesar de que habla de partir de la lengua viva, cotidiana, por ejemplo en la pág. 39), etc. Sobre el tratamiento de este último tópico, Ana Rita Romero aporta consideraciones críticas en las páginas 27 a 32 (Ver nota 20$)^{127}$.

4.4.7. No insiste suficientemente en el acercamiento inicial al texto literario con fines fundamentalmente lúdicos. Se puede percibir esto tanto en los objetivos (pág. 55) como en lo relativo a la literatura infantil (sobre todo págs. 100-108) ${ }^{128}$.

\footnotetext{
127 Sobre la corrección, la normatividad, véase: ARBOLEDA, Rubén. "Las Normas Lingüísticas En Revista Colombiana de Lingüística Bogotá, No. 6, junio de 1986, págs. 62-72.

${ }^{128}$ Como hemos visto, desde un punto de vista lingüístico se ha dado un acercamiento crítico a la nueva programación. No así desde una perspectiva literaria. Mucha falta está haciendo. Lo único que conozco, pobre y prejuicioso, fue dicho, sin eco, en el artículo de EL SIGLO mencionado anteriormente:

"¿LITERATURA O POLITICA?

"En los nuevos programas también se advierte que la literatura debe enseñarse conforme a la realidad política. Y como ejemplo se trae a García Márquez "y su visión" realista de la matanza de las bananeras. Si sabemos que el escritor de "Cien Años de Soledad" no sólo es un narrador sino un ideólogo de izquierda, los educadores se preguntan: ¿Quieren decir los programadores que enseñen a los escritores no tanto por su producción literaria sino por sus ideas politiqueras? ¿Que tipo de programas son estos?

Parece que a los reformadores no les convence que los niños puedan entender la gramática, pero en cambio sí les interesa que aprendan la literatura del "realismo político", que asen sana dialéctica un objetivo sencillo para politizar desde la infancia bajo el pretexto de analizar la realidad del país."

En 1986, el Grupo de Español y Literatura de la División de Diseño y Programación Curricular de Educación Formal del MEN, publicó Antología de la Literatura Infantil. Organizada por grados, de primero a quinto, contiene coplas, rondas, trabalenguas, mitos, leyendas, adivinanzas, fábulas, poesías, cuentos y teatro. Está precedida de un prólogo juicioso sobre la literatura infantil y la relación con ella de niños y adultos, el cual, además, aporta sugerencias metodológicas amplias, de mentalidad constructivista, no encasilladoras, para el disfrute y comprensión compartidos de la literatura. Algunos de los textos están antecedidos de comentarios sobre finalidades específicas de su lectura, razones de su presencia en la antología, tipo de lectura deseable, etc.
} 
4.4.8. El Marco General critica el análisis oracional que se ha practicado tradicionalmente, porque se basa en oraciones artificiales y aisladas. Tiene razón. Pero él mismo y los programas recaen en idéntico error: se quedan a nivel oracional, no tienen en cuenta el análisis del discurso o texto en general. Al analizar casos lógicos y al clasificar palabras recurren a los ejemplos más evidentes o a ejemplos construidos para el propósito, pero dejan de lado casos de alguna dificultad. Ejemplos del Marco son: María escribe con e/lápiz, el gato juega con la pelota, Juan escribe con su lápiz azul una carta a su papá, etc.

Sugiere analizar conversaciones de la vida real, pero casi nunca se hace. El programa de sexto grado (ver nota 25), para el análisis oracional propone: Willington y Claudia no trajeron la tarea, los alumnos de sexto grado organizan el centro literario (sic), Juan llegó cansado, el niño mono vive lejos, etc. No se insinúa siquiera la identificación y análisis oracional a partir de textos producidos por los alumnos.

El Marco incluye nociones sobre las funciones del lenguaje, lenguaje y emotividad, lenguaje y cultura y foco; pero no hace consideraciones sobre el análisis de estas realidades en discursos concretos. Quedan entonces como nociones para aprender, para memorizar; al menos eso puede suceder.

4.4.9. En el Marco General se insiste demasiado en que el programa se aleja de la parte teórica gramatical. De un lado, esto choca innecesariamente con las costumbres y creencias lingüísticas no sólo de muchos profesores sino del medio en general; la prueba es que se ha desatado toda una reacción frente a lo que en opinión general se ha denominado "la eliminación de la gramática en la escuela primaria". Si tenemos en cuenta que aún predomina la creencia de que "la gramática es el arte de hablar y escribir correctamente" y no el conocimiento de la estructura de la lengua, por ejemplo, podemos concluir lo que está pensando la opinión pública en general, con relación a los programas. Siendo las cosas así, valdría la pena que en el Marco General se definiera cuál es el concepto que se tienen de la gramática como ciencia del lenguaje y se detallara más el tipo de acercamiento a la lengua (gramática) que se sugiere no practicar en la primaria.

De otro lado, en La práctica no se registra un alejamiento radical de los programas en relación con los conceptos lingüísticos mínimos que el niño pudiera y debiera manejar, como se puede observar en el cuadro de contenidos básicos del Marco.

\subsubsection{Con regularidad se pide que el profesor actúe como modelo.}

Podría pensarse en otras formas: los alumnos mismos, miembros de la comunidad, grabaciones, etc.

4.4.11. No afronta sistemáticamente el análisis de los medios de comunicación, sus sistemas de producción de significados, su naturaleza, su función social, su "lectura".

4.4.12. Sobre atomización del proceso de enseñanza aprendizaje, circunscripción al nivel referencial, limitaciones en el sistema de evaluación y en la selección de las unidades y dimensiones del análisis, el grupo de Gloria Rincón aporta otras consideraciones (Educación y Cultura, No. 9). Sobre las limitaciones del sistema de evaluación el grupo de María Teresa Corrales también tiene datos interesantes (Ver la nota 20). 
4.4.13. Ana Rita Romero (Ver nota 20) señala la necesidad de un trabajo en lengua materna de desalienación del lenguaje, vinculado a un proyecto pedagógico alternativo y a un proyecto político ${ }^{129} ; \mathrm{y}$, entre otros aspectos del Marco, considera replanteables:

- Los "objetivos ideopolíticos". Encuentra contradictorio que por un lado se le asigne a la lengua el papel de "vincular valores morales, éticos y cívicos, con énfasis en el respeto a las instituciones", y por otro se diga que "... la utilización de la lengua debe conducir al hombre a la acción comunitaria transformadora de la realidad".

— La relación que establece entre educación, "buen manejo de la lengua", trabajo y "oportunidades de progreso material".

—La "mezcla ecléctica" de teorías "tanto en la parte lingüística, como en la psicológica"; la falta de adecuación de ellas, por ejemplo de "la psicología piagetiana" a las características del medio; la pretensión de "conciliar tendencias psicológicas y de pensamiento que por su naturaleza se repelen": Piaget frente a la rentabilidad de la educación y el diseño instruccional escogido, por ejemplo.

4.4.14. El Marco posee una buena cantidad de imprecisiones conceptuales y de pasajes sin desarrollo; una muestra se encuentra en el Anexo No. 3.

4.4.15. Hay otros aspectos débiles, pero menos pertinentes en este trabajo, por referirse a la composición. Puede verse una muestra en nuestro documento de 1982 (ver nota 9).

\subsection{El Marco General y el pensamiento sobre la enseñanza del lenguaje.}

Miremos ahora el Marco en el contexto del pensamiento general sobre la enseñanza del lenguaje. Para terminar, y en cierta manera globalizando, digamos que el Marco no presenta un panorama ascendente, una visión integral, en cierta manera universal del conocimiento sobre la pedagogía en general y de la lengua materna; no se ubica en la historia de esta disciplina. La característica no es exclusiva del Marco, también lo es, en general, de los centros de formación docente. Este hecho dificulta la percepción de la evolución de las temáticas, la valoración de diferentes propuestas, la modernización de nuestro quehacer, y muchísimo más la participación en el desarrollo del conocimiento existente. De ahí la importancia de remitirse a lo que consideramos tres momentos importantes para la conceptualización de la enseñanza del lenguaje, reacción frente a la pedagogía transmisionista: Las pedagogías activas, la psicolingüística de la lectura y ¡a escritura y ¡a relación escuela - códigos sociolingüísticos. En el documento Seminario sobre integración en el Diseño curricular - informe Final, (junio de 1982, los programadores del MEN pensaron en un rediseño curricular, a ja luz, entre otros elementos, de la "Escuela Activa". Infortunadamente, no sólo se trató de un proyecto, sino que el documento es propiamente posterior a la versión final de los marcos generales de ¡as áreas, como ya quedó mostrado en otra parte de este escrito.

Por lo pronto, y a manera de ejemplo, nombramos una bibliografía. La Editorial Labor publicó en 1937 una serie de cinco volúmenes consagrada a la pedagogía activa: el

\footnotetext{
${ }^{129}$ Sobre este último asunto también hay algunos planteamientos en:

Gallego, Rómulo y Pérez Unas. Ser y sentido de la Universidad. Bogotá, Universidad Pedag6gica Nacional, 1986.

Gantiva, Jorge. "Los Fines de la Educación y la Práctica Pedagógica”. En Educación y Cultura, No. 10 diciembre de 1986, págs. 612.

Vidal, Jesús María y otros. "Una Nueva Experiencia Pedagógica para Mejorar la Calidad de la Educación”. En Educación y Cultura, No. 10, págs. 50.53 .
} 
volumen 1 dedicado a la parte general: La escuela nueva y sus métodos: los otros, a la parte especial. La pedagogía activa del lenguaje está fielmente expresada en el volumen II, La enseñanza de/lenguaje, preparado por Domingo Tirado Benedí; obra sorprendente (aún mirada desde hoy), clásica y llamada a desempeñar una presencia irradiadora. De naturaleza similar es ja obra de Celestin Freinet, de la cual queremos destacar ahora: Los métodos natura/es 1. El aprendizaje de la lengua, Los métodos natura/es lii. El aprendizaje de la escritura y El texto Libre.

Desde la década de los setenta comienzan a aparecer resultados de los estudios de lectura y escritura que centran su atención en las relaciones entre el aprendizaje de la lengua escrita y el desarrollo cognitivo, que centran la atención en los procesos de construcción de la lengua escrita; esto, a partir de los avances de la psicolingüística, sustentada fundamentalmente en la gramática generativa transformacional y en la psicología genética, de Noam Chomsky y Jean Piaget respectivamente.

Se puede afirmar que en la lengua española tales estudios arriban a un momento significativo con la obra de Emilia Ferreiro y Ana Teberosky, Los sistemas de escritura en el desarrollo del niño, publicado en México por Siglo XXI editores, primera edición de 1979 (incluye una bibliografía importante); obra esta que ha ejercido una gran influencia entre quienes se ocupan del lenguaje y su enseñanza. En 1982, Siglo XXI publica Nuevas perspectivas sobre los procesos de lectura y escritura, compilación de Emilia Ferreiro y Margarita Gómez, a partir de los trabajos presentados en México, en el "Simposio Internacional sobre Nuevas Perspectivas en los Procesos de la Lectura y Escritura, organizado por la Dirección General de Educación Especial de la Secretaría de Educación Pública, que se llevó a cabo del 1 al 4 de julio de 1981". En esta compilación aparecen nuevos trabajos de Emilia Ferreiro y Ana Teberosky.

Louis Not, en el libro ya citado reconoce, vistas las cosas al menos a partir del siglo XVIII, tres momentos de la pedagogía. La pedagogía transmisionista o "de heteroestructuración"; "los métodos de autoes-tructuración, (...) métodos activos, (...) métodos de descubrimiento o de invención"; y ja de "interestructuración entre un sujeto que busca conocer y los objetos de su universo natural y cultural pertinentes a ese conocimiento". En la tercera parte, consagrada a la interestructuración, dedica una sección relativamente amplia al estudio del conocimiento y la enseñanza de jas lenguas, bajo esta perspectiva.

Paralelamente al estudio de la lectoescritura, y en general de la enseñanza del lenguaje, realizado a la luz de la psicolingüística, Brasil Bernstein ha desarrollado, desde una perspectiva sociolingüística, el estudio de los códigos lingüísticos (elaborado y restringido), ¡a función de jas instancias socializadoras (familia, escuela, etc.) en la inclinación de los individuos hacia uno u otro código, la relación entre la clase social a la que pertenece y tal inclinación etc. Mario Díaz, alumno de Bernstein y profesor de la Universidad del Valle, ha impulsado bastante estos estudios entre nosotros.

La revista Educación y Cultura de Fecode, ha publicado artículos del profesor Díaz en los números 4, 7 y 8 . Además, el Centro de investigaciones de la Universidad Pedagógica Nacional, CIUP, dedicó a este tema el No. 15 (1 semestre de 1985) de su Revista Colombiana de Educación.

La reflexión sobre las características de los discursos lingüísticamente elaborados, las implicaciones de su dominio o de la predominancia de uno u otro, y el papel que juega la 
escuela en todo esto, ha comenzado a generar replanteamientos en la pedagogía general y en la de la lengua materna en particular, primera responsable en la escuela (sabemos que lo deben ser todas) del desarrollo del lenguaje.

Tal vez no sea equivocado decir que los avances de la lingüística textual han creado condiciones favorables para experiencias y conceptualizaciones sobre la pedagogía del lenguaje que se están fraguando. Ya en 1 982, Alvaro Díaz, joven profesor de la Universidad del Atlántico, presentó unos primeros resultados al XV Congreso Nacional de Profesores de Lingüística (Bogotá, Universidad Distrital 1 982), en su ponencia La oración en el texto escrito.

Desde todo punto de vista, se percibe la urgencia de propuestas pedagógicas que integren los aportes de estos momentos de la pedagogía del lenguaje. Por supuesto, no se trata de yuxtaposiciones sin ninguna orientación definida; pero tampoco es exclusivismo que cierran los ojos dogmáticamente ante otras ideas. Se trata de establecer contacto con jos clásicos de la enseñanza del lenguaje, de ubicar y aprovechar los diferentes aportes integrables coherentemente a las propuestas resultantes de prácticas cultural-mente contextuadas, de evaluar y conceptualizar nuestras experiencias, de buscar nuevos desarrollos, de construir una tradición (un patrimonio); no de romper la continuidad o de querer eliminar de un brochazo, en aras de lo nuevo, como ya se insinúa en la "pedagogía conceptual", movimientos tan significativos como por ejemplo la Escuela Activa. Excepto, claro está, cuando se presenten nuevos paradigmas que necesariamente rompan con cualquier otra propuesta.

A partir de lo anterior se lograría además recuperar la visión de disciplina rigurosa, no de recetario didactista, que con justicia corresponde a la pedagogía del lenguaje, y que las instituciones la adoptaran como tal. Tanto las que nunca la han contemplado, como las que la han ido refundiendo (El Seminario Andrés Bello, por ejemplo) o ubicando en su segundo plano (caso de los departamentos de lenguas), con cierta razón, dado el didactismo dominante, producto de un normativismo lingüístico en alianza con la tecnología educativa de corte más conductista. ${ }^{130}$

\subsection{Conclusiones}

Hemos presentado los aspectos destacables del Marco General de Español y Literatura, y expresado nuestro acuerdo con Vasco y el grupo de Federici en que dicho Marco, como los de otras áreas, posee principios importantes. Pero a lo largo del trabajo hemos señalado limitaciones que lo hacen merecedor de una revisión seria.

Consecuentes con esto, consideramos importantes los trabajos de aclaración, precisión, reorientación y complementación, así como de sistematización de otras ideas, integrables a un marco de referencia para la enseñanza del español como lengua materna, que estimule la producción de conocimiento, el desarrollo cultural, la liberación de la palabra de educadores y alumnos..., a la luz de proyectos pedagógicos y políticos definidos; decimos integrables a un marco de referencia, porque éste nace del acopio y estructuración progresivos de aportes procedentes de distintas prácticas relacionadas con el asunto, es decir, de la constitución de una tradición.

\footnotetext{
${ }^{130}$ Actualmente adelantamos un estudio bibliográfico, relativamente amplio, del pensamiento sobre la enseñanza del lenguaje, que publicaremos posteriormente.
} 
Consideramos importante también la reflexión acerca de las Unidades integradas (entre áreas y al interior de las áreas mismas), como una de las prácticas acordes con un educador contextualizado y creador de conocimiento (en general, de cultura).

Quizás estos empeños y su expansión hagan resistencia a la reducción del educador a un ejecutor de instrucciones, que puede derivar además y en grado sumo de un uso despreocupado de múltiples manuales del mercado editorial. Con la misma dinámica que se ha abordado el análisis de la Nueva Programación han de abordarse los textos, determinantes básicos, de hecho, de la labor educativa.

Necesario se hace establecer contacto directo con las fuentes: reunir, reseñar, confrontar y relacionar distintas experiencias; y ubicar en este contexto los centros formadores de futuros docentes de lengua materna (Universidades y Normales), para que la acción adquiera un carácter cada vez menos remedial. 


\section{ANEXO No. 1}

\section{Inquietudes de Algunos Profesores del Distrito en relación con la Versión-81}

11. Para los docentes, formados en el enfoque tradicional, es dif (cii asimilar la clasificación de palabras desde un punto de vista no gramatical. Y el programa no da un código que oriente al maestro ni modelos que sirvan de guía para la realización de este trabajo; y es precisamente allí donde está la "novedad", pues el tratamiento metodológico de los otros aspectos, diálogo, descripción, narración, etc. en nada se diferencia de ¡o aprendido en las escuelas normales.

1.2. El programa da como ejemplos de palabras que nombran eventos únicamente a verbos y a nivel de palabras que designen cualidad a adjetivos. Hay cierta ambigüedad que apunta a realizar equivalencias y sustituciones de los dos puntos de vista, el morfosintáctico y el referencial, y crea desconcierto en el maestro.

1.3. Hace falta una orientación más precisa sobre qué persigue la literatura en la Básica Primaria: se deben dar algunas nociones sobre teoría literaria acorde con el nivel infantil, y señalar algunos autores y obras al alcance de la escuela; sobretodo de literatura infantil colombiana.

1.4. No se da orientación en cuanto al análisis de textos y creación literaria; tampoco en cuanto al análisis, desde el punto de vista "Semántico", de oraciones o fragmentos.

1.5. Ni los maestros ni las mismas unidades reflejan claridad en cuanto al significado de integración. Recomiendan revisar los fundamentos teóricos en los cuales está basada la estrategia de integración de las unidades ya elaboradas.

1.6. Algunos objetivos presentan dificultad ya que ciertos temas propuestos para realizar este trabajo no estén de acuerdo con el desarrollo intelectual de los niños.

1.7. Los programas descuidan la caligrafía y la ortografía.

1.8. Conviene utilizar tiras cómicas de cualquier periódico, puesto que éste constituye un excelente material para la recreación y la interpretación.

1.9. La evaluación es larga, minuciosa, engorrosa, esclavizante, encasilladora, dispendiosa, compleja, por cuanto el tiempo es escaso, los objetos numerosos y el número de alumnos excesivo.

El maestro debe tener libertad para escoger los objetivos que en su concepto deben ser evaluados.

\section{Recomendaciones de los "Técnicos" de la DIE-CEP en relación con la Versión- 81}

2.1. Definir en el marco teórico cuál es el concepto que se tiene de la gramática como ciencia del lenguaje y detallar más el tipo de acercamiento a la lengua (gramática) que se sugiere no practicar en la primaria.

2.2. Ampliar los planteamientos relacionados con el '>enfoque semántico" de tal manera que se clarifique la diferencia entre una clasificación de palabras de acuerdo con la realidad que nombran y otra que fundamenta la clasificación en las propiedades morfosintácticas y semánticas de clasificaciones no asimilables, dado el diferente punto de vista a partir del cual se ha establecido.

2.3. Aclarar la confusión entre la relación lenguaje-realidad, presente en el marco teórico con la oración "En la cadena hablada y escrita, objetos, eventos, cualidades y relaciones interactúan, por ejemplo 'El gato juega alegremente con la pelota roja' “

2.4. Elaborar unidades crecientes progresivamente en complejidad y extensión que tengan en cuenta el desarrollo del mayor número de destrezas, según su correlación, que presenten breves contenidos teóricos en la medida que éstos sean útiles para el 
desarrollo de las destrezas (concepto de oración, de nombre, de adjetivo, de verbo, de sílaba, etc., por ejemplo).

2.5. Elaborar una estructura de temas generadores por curso, ya que ellos marcarán en gran medida el creciente grado de complejidad. Los temas deben cumplir con los siguientes requisitos: que partan de la experiencia del niño, que lo integren a la vida familiar y social, que lo lleven a tomar conciencia de sí mismo, de su situación dentro de la sociedad y de su papel histórico como agente de cambio (como lo postula el marco teórico>. Estos temas generadores guiarán la selección de textos (con frecuencia arbitraria y poco técnica) que estén de acuerdo con el vocabulario progresivo que debe ir adquiriendo y ejercitando el niño (sobre esto también debe haber indicaciones), y que debe ser evaluado en su adquisición y manejo (según indicaciones del marco teórico>. Guiarán, también, una selección de textos acorde con este postulado del marco conceptual: "En la enseñanza del Español se debe partir de ja lengua inmediata, viva, cotidiana".

2.6. Establecer relaciones con los centros formadores de futuros docentes para que éstos salgan preparados para abordar los Programas. De lo contrario se seguirá en el problema de no encontrar personal apto para brindar capacitación a los docentes en ejercicio.

2.7. Elaborar material de apoyo para los docentes en cuanto al enfoque semántico y sintáctico.

(Arboleda, Rubén. Comentario al Programa Experimental... Págs. 3 a 6, 15 a 16).

\section{ANEXO No. 2}

1. Características de la Versión de febrero de 1982 en relación con la de 1981

1.1. Complementación de estos aspectos:

Lenguaje, lengua y habla (pág. 3).

- Necesidad de que el estudiante capte para qué sirve la lengua (pág. 8).

- Esquema de Luis Angel Baena para mostrar el proceso desde la representación conceptual de la realidad hasta la expresión (pág. 10 y s.s.).

- Objeto, evento, cualidades y relaciones (pág. 11-14).

- Relaciones entre las categorías de la realidad y las categorías léxicas (pág. 23-24).

- Enfoque de la literatura (pág. 26-32).

- $\quad$ Propósito de desarrollar las habilidades comunicativas (pág. 32).

- La expresión oral y escrita (pág. 33-38).

- Diálogo, narración, descripción (pág. 49-58).

- Lectura de signos lingüísticos (pág. 80-85).

- Literatura infantil (análisis de textos y creación literaria) (pág. 85-114).

- Biblioteca escolar (pág. 114-117).

1.2. Inserción de estos aspectos:

- Introducción general.

- Dialecto (pág. 3).

- Justificación, por medio de Piaget, de la necesidad de partir de la lengua viva del estudiante y de revelar el estudio de la gramática para la segunda enseñanza (pág. 7.).

Referencias bibliográficas para respaldar el concepto de objeto (pág. 10-11).

Relaciones lenguaje-pensamiento según Vigotsky y Piaget y desarrollo del niño según Piaget (pág. 15-20). 21-23).

La emotividad y su expresión en el lenguaje, lengua y acción, lengua y cultura (pág.

- Ortografía, acentuación, puntuación (pág. 38-39). 
- El resumen (pág. 58). El informe (pág. 59). La exposición (pág. 60).

- Entonación, intensidad y matices afectivos de la voz (pág. 61-68).

- Ejercitación de la morfosintáxis a través de la semántica (información nueva y dada, casos lógicos).

Relación lenguaje-realidad, lenguaje-intención comunicativa, información nueva y dadasujeto y predicado (pág. 68-77).

- $\quad$ La lectura de signos no lingüísticos (pág. 77-80).

- Literatura infantil. Análisis de textos (pág. 89-107).

- Técnicas grupales (pág. 117-120).

- Evaluación en Lengua y Literatura (pág. 120-1 59).

- Contenidos básicos da 10. a 9o. (anexo).

- Bibliografía (anexo).

\section{Variaciones de la Versión de agosto de 1982 en relación con la de febrero del mismo año}

\subsection{Reordenaciones:}

- Los objetivos, que pasan al literal B (pág. 22-23), y los cuadros de contenido por grado que se reagrupan bajo el literal C: Estructura conceptual del área (pág. 25-43).

Las consideraciones sobre ortografía de las págs. 38-46.

2.2. Supresiones:

- Los tres primeros párrafos de la introducción, relacionados con: el marco legal de los programas, una síntesis de la historia de la renovación curricular y quiénes hicieron aportes para la revisión del programa (cuestionable, por la importancia de la información).

- Ortografía: ejercicios de asociación semántica de la pág. 45.

- $\quad$ La puntuación (pág. 48).

- $\quad$ La descripción (pág. 59).

- Entonación, intensidad y matices afectivos de la voz (pág. 61-68 y 83-84). Cuestionable, porque el tema fue solicitado con razón por el magisterio.

- Intención comunicativa (pág. 72-74).

- Consideraciones sobre sujeto y predicado (pág. 74-75).

- Algunos párrafos sobre lectura de signos no lingüísticos y lingüísticos y literatura infantil. Algo referente a que el maestro debe servir de modelo (pág. 77-80, 84, 85-88).

- Un párrafo de la pág. 85 que señala a la integración como un criterio para la selección de textos.

Cuestionable porque el criterio es muy válido.

- Aspectos relacionados con el qué, por qué y cómo evaluar, y con el cómo proceder (pág. 120-125, 136-137).

- Evaluación de los distintos niveles de lengua (pág. 137-138).

- Otros aspectos de la evaluación (pág. 146-159).

\section{ANEXO No. 3}

\section{Imprecisiones Conceptuales del Marco}

Página 33:

Dice: "La base de la comprensión al escuchar y leer, y de la propiedad y corrección en la expresión oral y escrita, es el conocimiento, por parte del niño, de la relación que existe entre la realidad, el pensamiento y la lengua, o sea la significación".

¿A qué tipo de conocimiento se refiere? Seguramente no será a un conocimiento lingüístico teórico. 


\section{Página 35:}

Dice: "Dichos sistemas poseen reglas a través de las cuales se establecen relaciones de combinación, ordenamiento y prohibición entre los elementos significativos o signos". Resultaría menos idealista decir: Por cuanto entre los signos se dan relaciones, constituyen sistemas.

Es conveniente definir e ilustrar las relaciones. ¿Cuáles son las de prohibición, por ejemplo?

Dice: "El lenguaje es tanto social como individual. Por ser de carácter social se hace posible la comunicación entre dos o más personas que conozcan y manejan el sistema. Por ser individual cada persona lo puede utilizar e interpretar". Resultaría menos idealista decir: Por utilizarse para la comunicación entre dos o más personas que conozcan y manejen el sistema, es social; por ser utilizado e interpretado, es individual.

\section{Página 36:}

No da la diferencia específica de lengua. La música también es un medio de expresión individual.

\section{Página 38:}

Dice: "La lengua debe ser perfeccionada en la Básica Primaria a través de la práctica y estudiada científicamente a través de la teoría en la Básica Secundaria y Media Vocacional. El perfeccionamiento de su manejo será contenido del área en todos los niveles del sistema educativo".

El enunciado es muy radical; podría mejorarse, así: En todos los niveles, fundamentalmente en la Básica Primaria, se atenderá al desarrollo de las habilidades comunicativas; particularmente en la Básica Secundaria se atenderá al estudio científico de la lengua.

El "perfeccionamiento de su manejo (de la lengua)" no debe considerarse un contenido sino una tarea.

\section{Página 39:}

Dice: "A partir de estos niveles, el educando, con base en la larga práctica que habrá tenido durante la Básica Primaria, podrá descubrir los fundamentos teóricos de la lengua y aprender más fácilmente la coherencia entre los diversos niveles de la lengua (fonético, fonológico, morfosintáctico y semántico) y la realidad que ella designa".

Creo que no se trata de "descubrir los fundamentos teóricos" sino de aprehenderlos, inducirlos, y, de pronto, de teorizar la lengua.

\section{Página 47:}

Dice: "Los niveles de Configuración Morfosintáctica, Configuración Fonológica y Forma Fonética o Gráfica constituyen las estructuras sistemáticas de la lengua”. 80:

¿Lo semántico no formará parte de "las estructuras sistemáticas de la lengua? Página

Dice: "Si el niño no ha acentuado bien las palabras, se le pedirá que dé ejemplos de palabras que se acentúan en la misma sílaba para que transfiera la acentuación oral al nivel escrito".

¿Puede transferirse la acentuación oral al nivel escrito? 


\section{Página 82:}

Dice: "En relación con la representación gráfica de la acentuación de las palabras, por ser un fenómeno que va ligado íntimamente a la pronunciación, la ejercitación escrita debe hacerse siempre precedida de la ejercitación oral".

¿A todas las palabras se les representa gráficamente la acentuación?

\section{Página 90:}

Dice: "Al comienzo del Marco General se afirmó que el lenguaje es la facultad que tiene el hombre para comunicarse y que la lengua es el instrumento que utiliza para lograr esa comunicación".

Tal vez no sea el instrumento sino un instrumento.

\section{Página 134:}

Dice: "Encierre en un círculo el número correspondiente para la siguiente pregunta:

\section{Ejemplo:}

¿Cuál de las siguientes oraciones parece más natural?

1. Una carta para mí el criado trajo.

2. Para mí una carta trajo el criado.

3. El criado trajo una carta para mí.

4. El criado una carta trajo para mí".

¿Qué significa más natural? ¿Querrá decir: de uso más común? Porque todas son gramaticales; y si aquí natural significa gramatical, todas lo son.

\section{Pasajes sin desarrollo. Dos ejemplos:}

\section{Página 36:}

Dice: "El español es la lengua común de todos los colombianos. Para los grupos indígenas de Colombia y para los nativos de San Andrés y Providencia, que tienen sus propias lenguas maternas, el español es su segunda lengua; para el resto de los colombianos es la lengua materna".

\section{Página 38:}

Dice: "La utilización de la lengua debe conducir al hombre a la acción comunitania transformadora de la realidad". 